\title{
COMPARISON OF THE EFFECT OF NUCLEOTIDES AND BREWER'S YEAST ON SPECIFIC IMMUNITY OF BROILER CHICKENS IN SYRIA
}

MONA AL. SHARABI

PhD of Poultry Diseases, Faculty of Vet. Med., Al-Baath University, Hama, Syria

\section{ABSTRACT}

The study was conducted on (300) commercial broiler chickens, for Comparison of

Received at:21/4/2013 the effect of Nucleotides and Brewer's Yeast on specific immunity of infectious bursal disease (IBD) after vaccination. The study has confirmed that there were clear significant variations between control and study groups which added to its feed Nucleotides and Brewer's yeast during all stages of breeding for titers antibodies for IBD ( $\mathrm{P}$ value $=0.0001)$. The study has confirmed that there were clear significant variations between the study groups (group1, group2) which added to its feed Nucleotides and yeast beer during all stages of breeding for titers antibodies for IBD $(\mathrm{P}$ value $=0.001)$. in comparison with the control group.

Key Words: Nucleotides, Yeast, Specific immunity.

\section{مقارنة تأثير النيوكليوتيدات النووية مع خميرة الخبز على المناعة النوعية لاجاج اللحم في سوريا}

$$
\text { منى الشرابي }
$$

أجريت الدر اسة على ( · ·r) طيرٍ من إحدى الهجن التجارية لدجاج اللحم بغية مقارنة تأثير المحسنين المناعيين وهما النيكلوتيدات النووية وخميرة

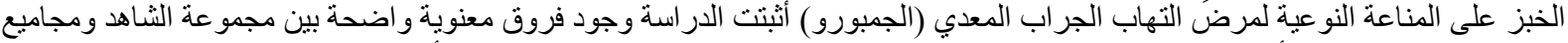

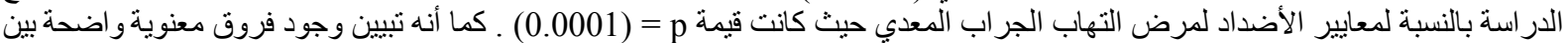

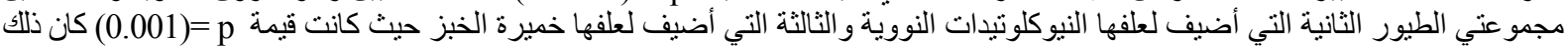

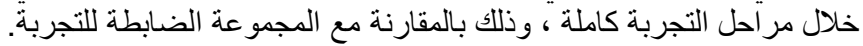

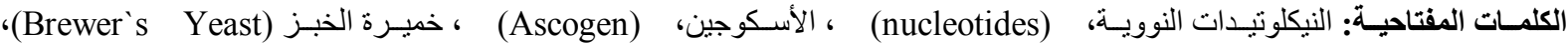
(Specific Immunity of Broiler Chickens) (للحناعة النوعية عند دجاج النحة)، (Sacharomyces Cerevisiae)

\section{مقدمـة \\ INTRODUCTION}

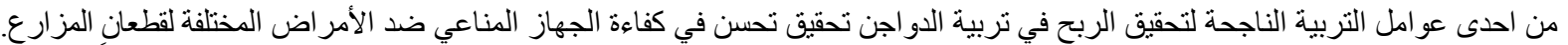

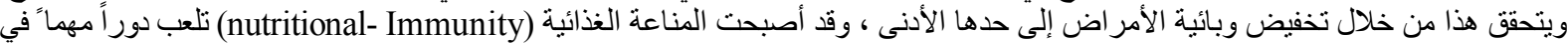

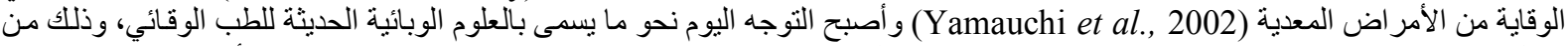

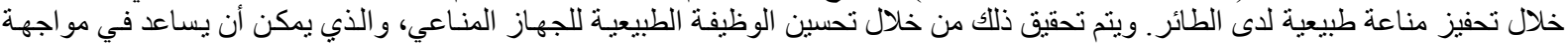

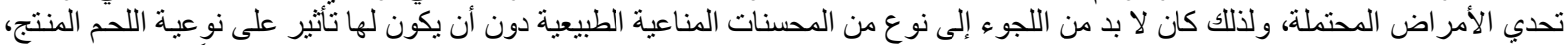

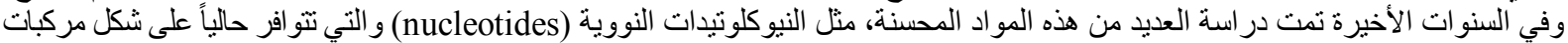

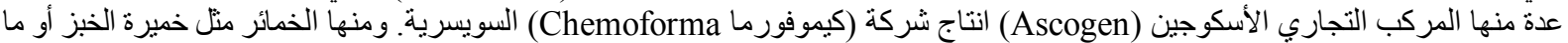
يدعى بالاسم العلمي سكارو ميسيس سيرفيسيا Saccharomyces Cerevisiae و هي منتجات محلية ، و غير ها الكثير.

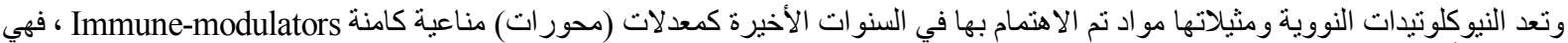

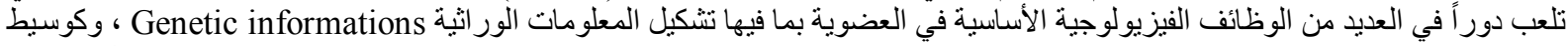

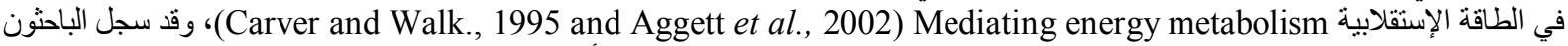
Cell - البرن (Aggett et al., 2002 and Adjei, 1993)

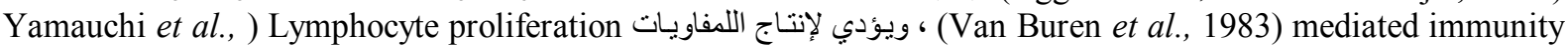

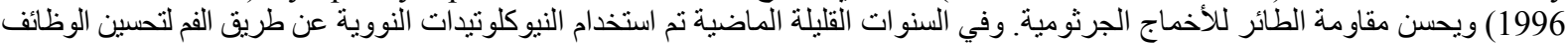

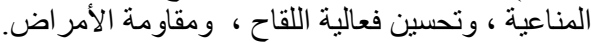

كما نم استخدام خميرة الخبز أو البيرة Brewer`s yeast ، أو ما يدعى بالاسم العلمي سكاروميسيس سبرفيسيا Saccharomyces Cerevisiae.

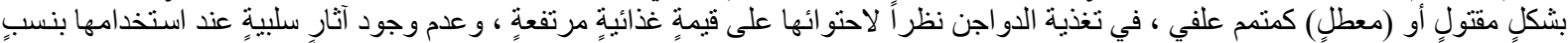

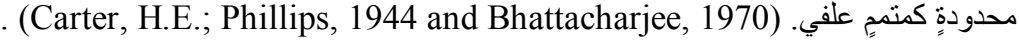




\section{Assiut Vet. Med. J. Vol. 59 No. 138 July 2013}

فهي تتميز بمحتوى مرتفع من النيوكلوتيدات النووية ، إلا أن استخدامها بكمياتٍ كبيرةٍ ينجم عنه سوءٌ هضميٌ (اضطر اب عمليات الهضم). (Carter and Phillips,1944)

كما وجد الباحث (Stone, 1998) ، أن استخدام خمبرة سكاروميسيس سيرفيسيا في تغذية دجاج اللحم كمادٍٍ طبيعيةٍ توفر الفيتامينات وخاصـة مجموعة فيتامين B وكذلك البروتين ذو القيمة البيولوجية العالية.

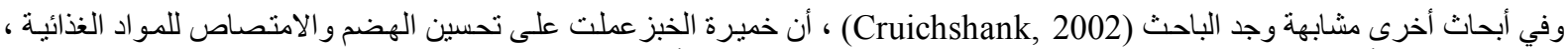

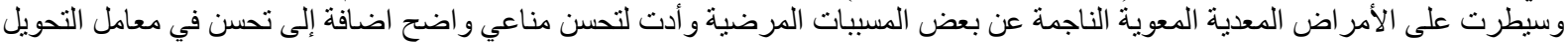
العلفي.

كما وجد الباحثون (Mickolos et al., 2003) أن مشاركة التحصين مع اعطاء محسن مناعي ، أدى لزيادة في مستوى معيار الأجسام المضادة

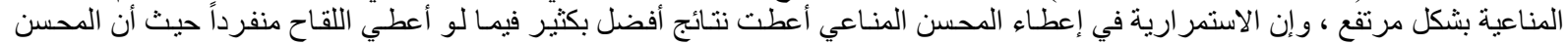
المناعي زاد من نسبة الحماية عند التحصين.

\section{مواد وطرق العمل \\ MATERIALS and METHODS}

مواد العمل: Materials

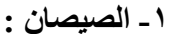

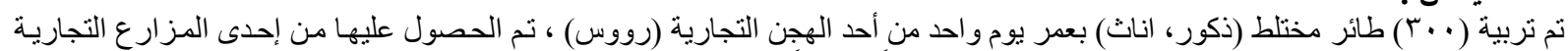
لتربية قطعان أمات دجاج اللحم (الفروج) ، ،قدمت للطيور عليقةً محبحبةً بمر احل مختلفة (مرحلة أولى ومرحلة ثانية).

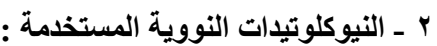

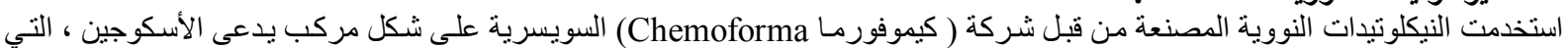
استخدمت على شكل بودرة تم خلطها مع العلف المستخدم حسب خطة الدر اسة ( . . . ( جر ام /طن) أثناء عملية تصنيع العلف المستخدم في التجربة.

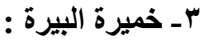

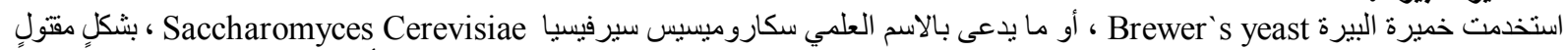

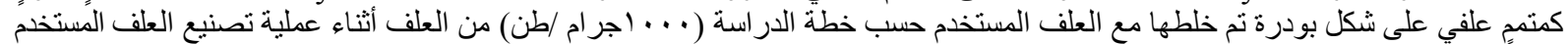

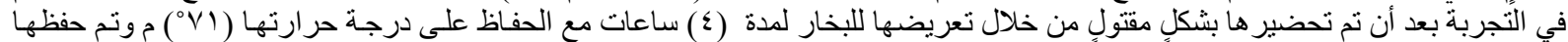

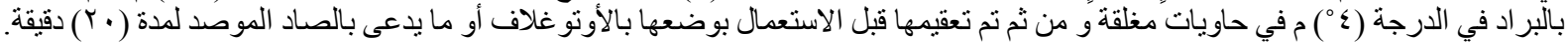

Methods : طرق العمل

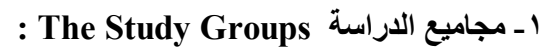

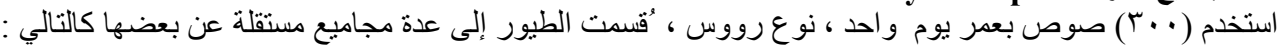

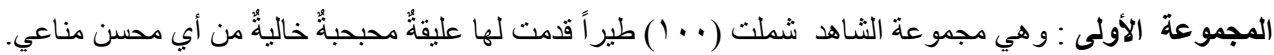

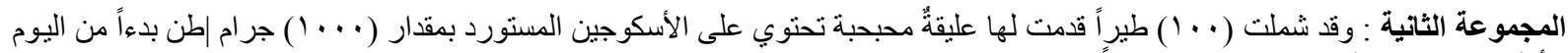
الأول وحتى نهاية التجربة بعمر (0؛ (1) يوماً.

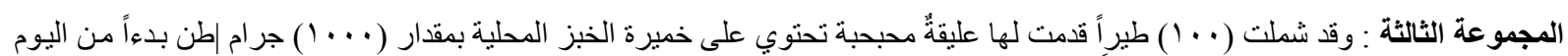
الأول وحتى نهاية التجربة بعمر (0 ( ) يوماً.

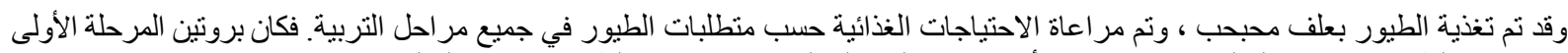

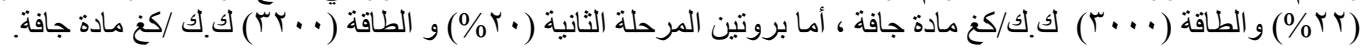

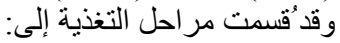
مرحلة أولى مفتت من عمر يوم إلى عنى عمر (10) (10) يوماً.

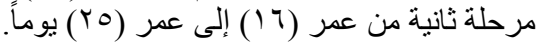

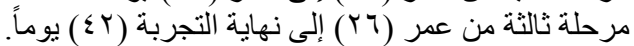

وتم تحصين الطيور لجميع مجاميع الدراسة بنفس جر عة ونو عية اللقاح كما هو موضح بالجدول رقم (1)

الجدول رقم 1: برنامج تحصين طيور التجربة.

\begin{tabular}{|c|c|}
\hline اسم اللقاح & العمر بالأيام \\
\hline لقاح التهاب القصبات المعدي (حي) العترة Mas5 عن طريق ماء الثرب & $\Lambda$ \\
\hline لقاح النيو كاسل HB1 عن طريق ماء الثرب & 11 \\
\hline لقاح الجمبورو (حي) عن طريق ماء الثرب & 10 \\
\hline لقاح نيو كاسل (حي) CLONE عن طريق ماء الثرب & $r \wedge$ \\
\hline
\end{tabular}




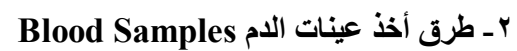

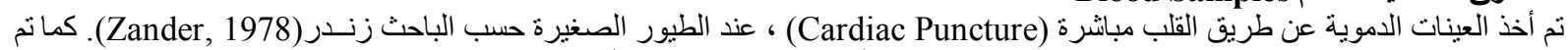

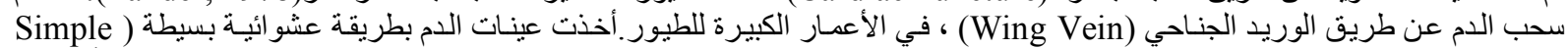

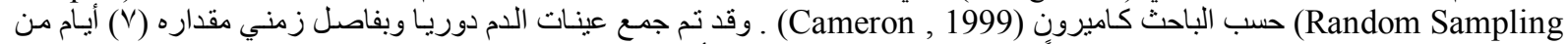

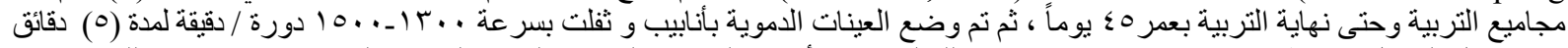

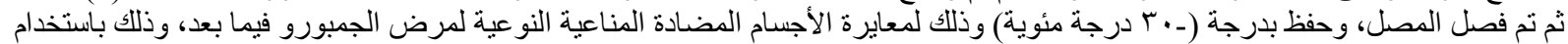

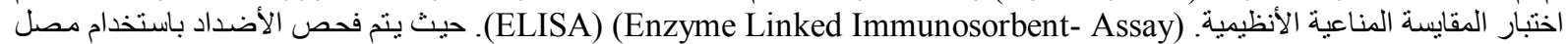
ممدد بتمديد (1: (0) في أطباق اختبار الإليز ا والحاوية على (97) حفرة.

: Serological Tests الاختبارات المصلية

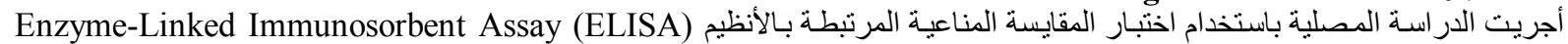

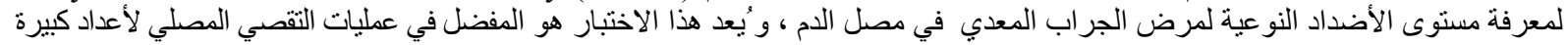
من العينات بالنسبة لمرض الجراب الاب المعدي (IBD) (Lee and Lin, 1992). واستخدمت طريقة البحاحثون (Pick and Mizel., 1981). لإجر اء الاختبار وخطوات العمل حسب توصنيات الثركة المعدي المنتجة للمجمو عة التشخيصية.

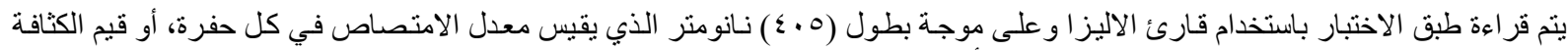

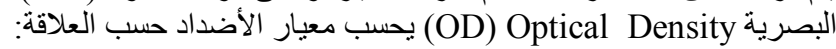

$\mathrm{S} / \mathrm{P}=($ Abs Test Sample - Abs Negative $) /($ Abs Positive - Abs Negative $)$

$\log 10$ Titre $=0.870 \times(\log 10 \mathrm{~S} / \mathrm{P})+3.92$

Titre $=$ Antilog of $\log 10$ Titre

ع ـ طريقة التحليل الإحصائي Statistic Analysis Method

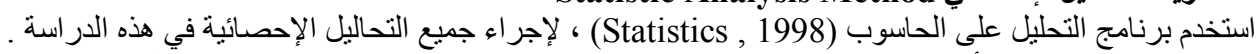

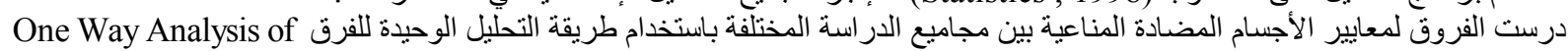
.Variance

\section{النتائج \\ RESULTS}

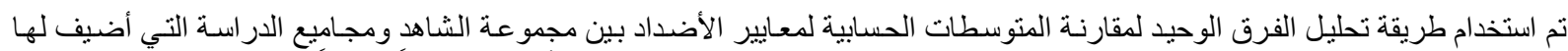

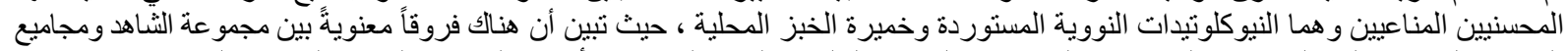

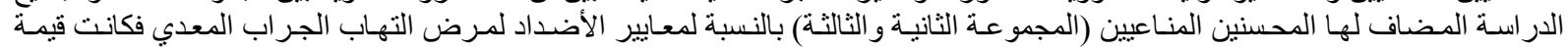

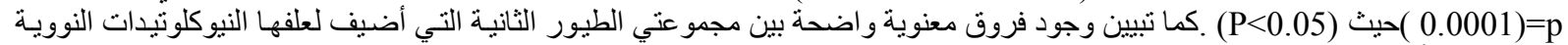
والثالثة التي أضيف لعلفها خميرة الخبز فكانت قيمة p>0.01 (0.001 ) حيث (P>0.05) كان ذلك خلال مر احل التجربة كاملة.

يوضح الجدول رقم (r) مقارنة قيم المتوسطات الحسابية لمعايير الأضداد لمرض التهاب الجراب المعدي باستخدام طريقة تحليل الفرق الوحيد بين

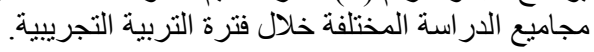

جدول رقم ؟ ؛ منوسط معايير الأضداد لمرض التهاب الجراب المعدي 土 الانحر اف المعياري.

\begin{tabular}{cccc}
\hline عمر الطيور (يوم) & (المجموعة الأولى الثاهد & $\mathbf{5}$ \\
\hline $1273.8 \pm 3522.7$ & $2210.3 \pm 5915.5$ & $1173.8 \pm 3322.7$ & $\mathbf{1 3}$ \\
\hline $1233.6 \pm 3828$ & $1212.92 \pm 11796$ & $1758 \pm 3346.4$ & $\mathbf{2 2}$ \\
\hline $3306.4 \pm 5342$ & $2205.4 \pm 13036$ & $2572.8 \pm 4050.2$ & $\mathbf{2 9}$ \\
\hline $2984.7 \pm 5445.7$ & $1173.8 \pm 14271$ & $2330.8 \pm 4415.9$ & $\mathbf{3 6}$ \\
\hline $3495.6 \pm 7950.4$ & $1343.2 \pm 17271$ & $1667.7 \pm 6491$ & $\mathbf{4 2}$ \\
\hline $6060.4 \pm 15528$ & $3473.5 \pm 21994$ & $2978 \pm 8584$ & $\mathbf{4}$ \\
\hline
\end{tabular}

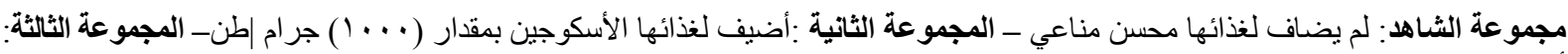

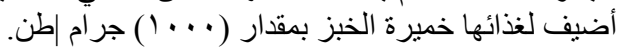




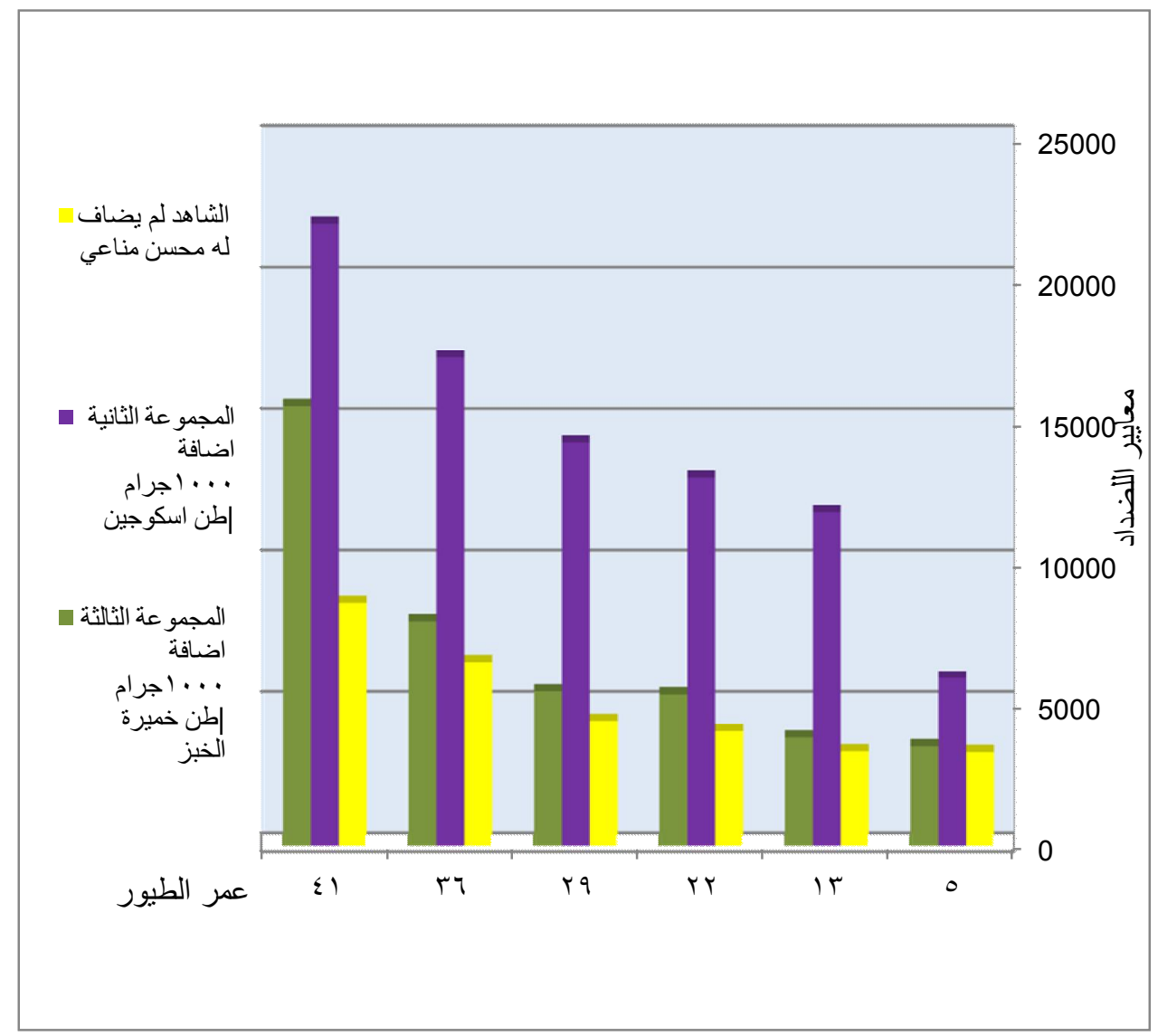

مخطط (1) متوسط معايير الأضداد لمرض التهاب الجراب المعدي لمجاميع الدراسة

المناقثة

DISCUSSION

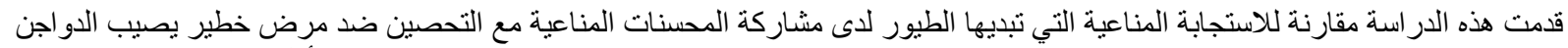

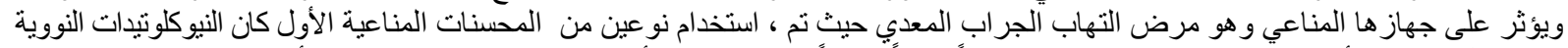

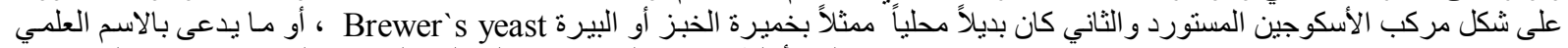

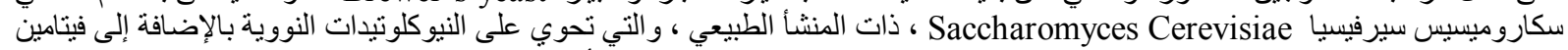

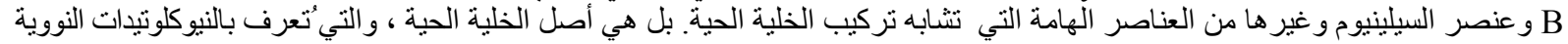

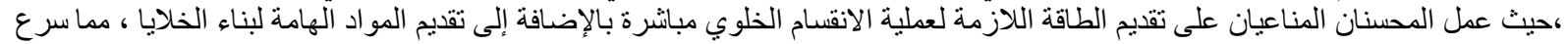
في عملية الانقسام الخلوي.

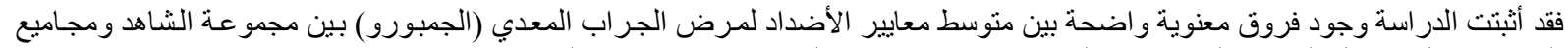

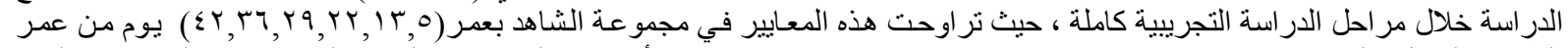

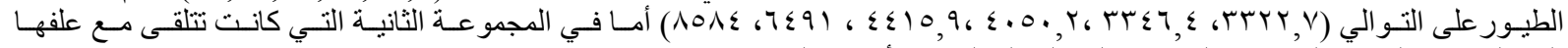

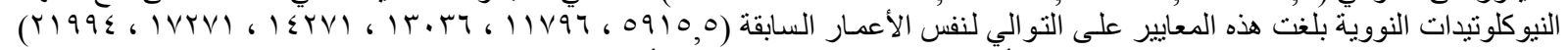

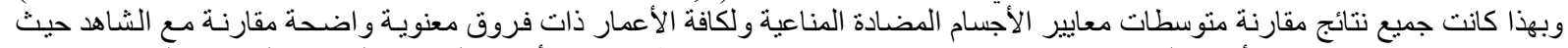
كانت قيمة (

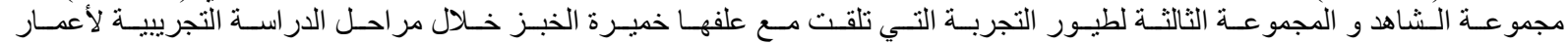

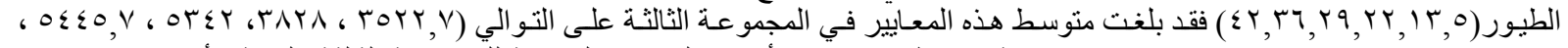

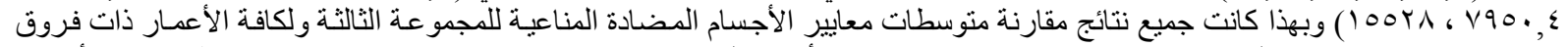

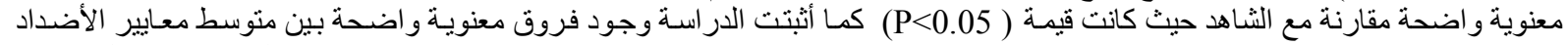

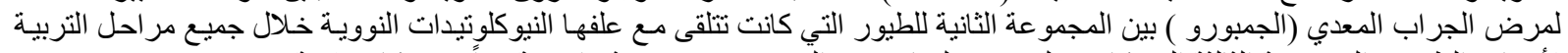
لأعمار الطيور و المجمو عة الثالثة التي كانت نتلقى مع علفها خميرة الخبز بفروق معنوية واضحة جداً حيث كانت قيمة (P<0.05).

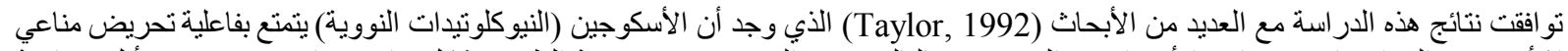

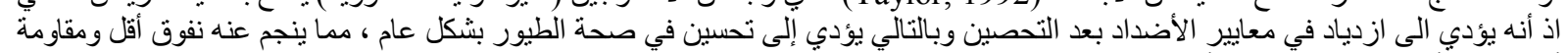

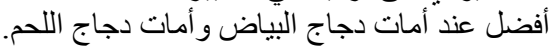


وتو افقت أيضاً مع الباحث (Hamet, 1992) حيث أثتبت أن النيكلوتيدات النووية تعمل كمفعل ور اثي حيوي لنكاثر الخلايا البشرية ، ولها دور في المناعة الخلوية وبهذا تسمح للحيو انات بآلية دفاعية محسنة.

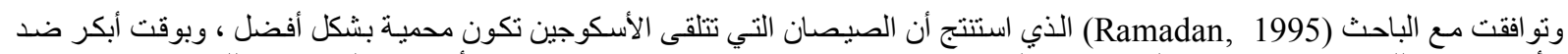

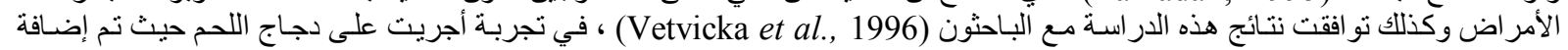

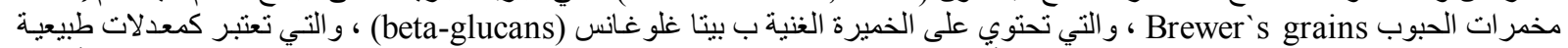

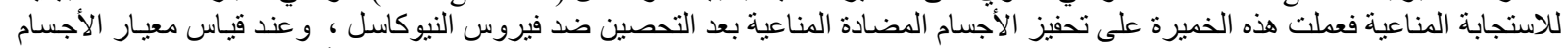

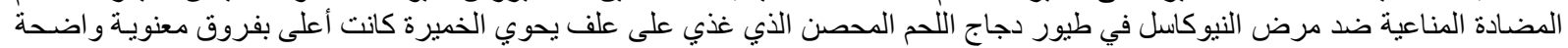

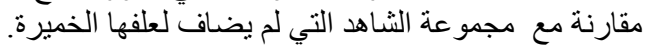

تو افقت هذه الدر اسة أيضاً مع (Onifade and Babatunde, 1998) حيث أن إضافة خميرة الخبز يؤدي لزيادة الوزن وزيادة مقاومة الطائر

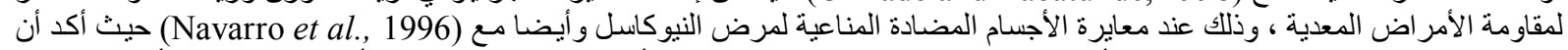

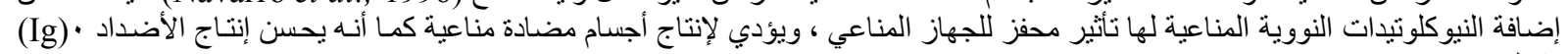

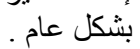

Yalcin et al., 1993 and ) وتو افقت هذه النتائج مع العديد من الأبحاث السابقة التي استخدمت خميرة الخبز كحسن للمناعة وللنمو حيث وجدأ (Yadav et al., 1994

وتو افقت مع الباحث (Damron, 2005) الذي تناول في دراسته العديد من المحسنات المناعية ومحسنات النمو كالعصبات اللبنية وبعض الخمائر و لاحظ ان جميعها يعمل على تحريض الاستجابّة المناعية وبدرجات متفاوتة وبطرق آلية متقاربة التأثئير على الجهاز المناعي.

\section{(الاستنتاج \\ CONCLUSION}

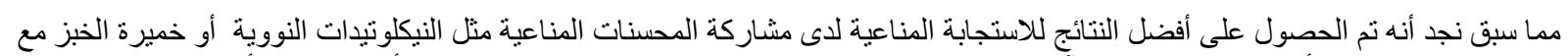

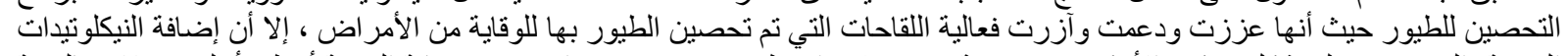

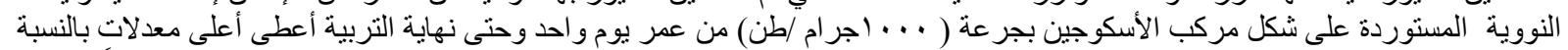

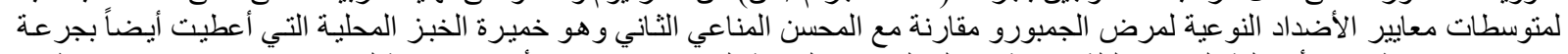

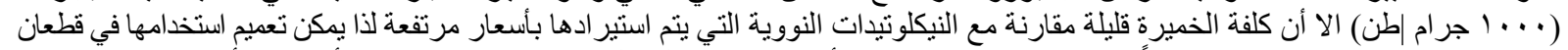

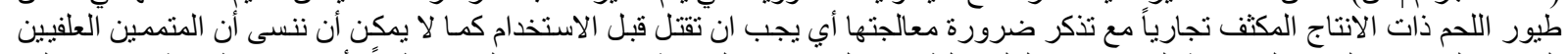

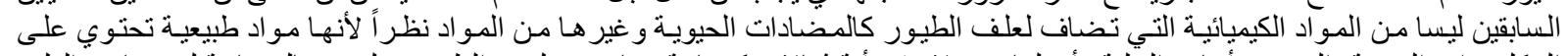

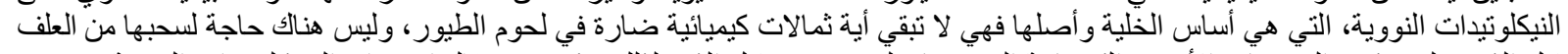

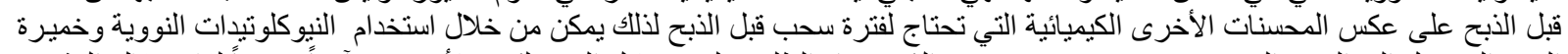

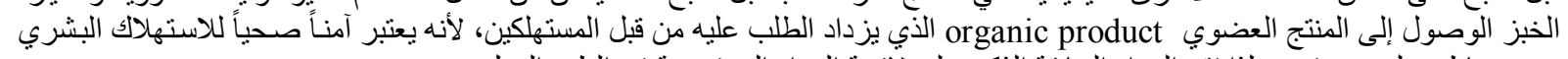
دون مخاطر على صحته ، ولذا تقع المو اد السابقة الذكر على لأنحة المو اد الكستخدمة في الطب البديل.

\section{المراجع \\ REFERENCES}

Adjei, A.A.; Takamine, F.; Yokoyama, H.; Shiokawa, K.; Matsumoto, Y. and Asto, L. (1993): The effects of oral RNA and Intraperitoneal Nucleoside- Nucleotide Administration on Methillin- Resistant Staphylococcus Aureus Infection in Mice. Journal of Parenter Enteral Nutrition. Vol. 17, No. 148-52

Aggett, R.; Leach, J.L.; Rueda, R. and Maclean, W.C. (2002): Innovation in Infant Formula Development: A Reassessment of Ribonucleotides. Nutrition Journal, Vol. 19, No. 375-84.

Bhattacharjee, J.K. (1970): Microorganismes Potential Souces of food. Adv. Appl.Microbiol. Vol. 13., No. 139. Cameron, A. (1999): Survey Tool Box for Livestock Diseases: A practical Manual and Software Package for Active Surveillance in Developing Countries. Australian Centre for International Agricultural Research. Australia.

Carter, H.E. and Phillips, G.E (1944): The nutritive Value of yeast Protiaus. Fed. Proc. Vol. 3, No. 123.

Carver, J.D. and Walker, W.A. (1995): The role of Nucleotides in Human Nutrition. Nutural Biochemical Jornal, Vol. 6, No. 58-72.

Cruichshank, G. (2002): Gut microflora the key to healthy broiler growing. Poultry World, July, 14.

Damron, B.L. (2005): Flavoring for Poultry. Report by the University of Florida, IFAS Extension, USA.

Hamet, N. (1992): Reinforcement of the Defense Against Coccidiosis Report. CNEVA, PLOUFRAGAN, Farance 
Lee, L.H. and Lin, Y.P. (1992): Amonoclonal antibody capture enzyme - linked Immunosorbent assay for Detecting antibodies to infectious bursal disease virus.Journal of virological methods, 36: 13-23.

Mickolos, D.A.; Fewyer, G.A. and Crotty, D.A. (2003): DNA Science. Cold Spring Harbor Laboratory Press. Publisher, John Inglis. USA.

Navarro, J.; Ruiz-bravo, A.; Jimenez-Varela, M. and Gil, A. (1996): Modulation of Antibody-Forming Cell and Mitogen- Driven Lymphoproliferative Response by Dietary Nucleotide in Mice. Immunology Journal, Vol. 53, No. 141.

Onifade, A.A. and Babatunde, G.M. (1998): Comparisonthe utilization of palm kernel meal, brewers' driedgrains and maize offal by broiler chicks. Br. Poult.Sci., 39: 245-250.

Pick, E. and Mizel, D. (1981): Rapid Microassays for the Measurement of Superoxide and Hydrogen Peroxidase Production by Macrophages in Culture Using an Automatic Immunoassay Reader. Journal of Immanuel Methods, Vol: 46:211-26.

Ramadan, A. (1995): Poultry Immunology $24^{\text {th }}$ Poultry Science Symposium of the WPSA, UK, Reading University, England.

Statistics, (1998): Analytical Softewar, Guideline manual, Version, 2.0. USA.

Stone, C. (1998): Yeast products in the feed industry. Ed. By Mills, d. Inc. Cedar Rapids, Iowa., p. 10-11.

Taylor, J. (1992): ASCOGEN, Biogenic Performance Enhancer, University of Glasgow, UK.

Van Buren, C.T.; Klkarni, A.D.; Schandle, V.B. and Rudolph, F.B. (1983): The Influence of Dietary Nucleotides on Cell-Mediated Immunity. Transplantation Journal, Vol. 36, No. 350-2.

Vetvicka, V.; Thornton, B.P. and Ross, G.D. (1996): Soluble beta-glucan polysaccharide binding to the lectin of neutrophil or natural killer cell complement receptor type $3(\mathrm{CD} 11 \mathrm{~b} / \mathrm{CD} 18)$ generates a primed state of the receptor capable of mediating cytotoxicity of iC3b-opsonized target cells. J. Clin. Invest., 98: 50-61.

Yadav, B.S.; Srivastava, R.K. and Shukla, P.K. (1994): Effect of supplementation of the broiler rationwith live yeast culture on nutrient utilization and meat production. Indian Journal of Animal Nutrition, 11 (4): 225-227.

Yalcin, S.; Onol, A.G.; Kocal, D. and Ozcan, I. (1993): The use of baker's yeast as a protein source in broiler ration. Doga, Turk- Veterinerlik-ve-Hayvancilik-Dergisi, 17 (4): 305-309.

Yamauchi, K.; Hales, N.W.; Robinson, S.M.; Niehoff, M.L.; Ramesh, V. and Pellis, N.R. (2002): Dietary Nucleotides Prevent Decrease in Cellular Immunity in Ground-Based Microgravity Analog. Journal of Applied Physiology. Vol. 93, No. 161-6.

Yamauchi, K.; Adjei, A.A.; Ameho, C.K.; Chan, Y.C. and Kulkarni, A.D. SATA. (1996): A nucleoside-Nucleotide Mixture and Its Components Increase Lymphoproliferative and Delayed Hypersensitivity Responses in Mice. Journal of Nutural, Vol. 126, No. 1571-7.

Zander, D.V. (1978): In Disease of Poultry (7 ed) Iowa State University Press. PP.3. 